\title{
Analysis of the Reasons of Public High School Students in United States Choosing Chinese as a Foreign Language
}

\author{
The Case of Nevada
}

https://doi.org/10.3991/ijet.v12i06.7092

Haihuai He

Wenzhou Vocational \& Technical College, Zhejiang, China

$374183657 @$ qq.com

\begin{abstract}
The research focuses on the motivations of US's high school students chose Chinese as a secondary language study programme from multiple aspects: the future career considerations, Chinese population growth, and the persona interests. The current Chinese language learning statistics have been given as further references in terms of questionnaire findings.
\end{abstract}

Keywords-US high school, students, Chinese language, motivation of studies

\section{Introduction}

Currently, English is the most widely used language around the world. An American student, especially high school students, often lacks the motivation to learn a foreign language. Native English-speaking high school students may think that the foreign languages is not necessary because no matter which country they are going to, there are always people who can speak English in that country. For now, in all fifty states of America, it is required that high school students take a foreign language class in order to graduate, based on the study of National Council of State Supervisors for Language. In Nevada, students are required to finish at least two credits of the foreign language courses. In Chapter 1 of 2013 Nevada Education Data Book, A 2010 study titled "Education Data Profiles for the State of Nevada and Surrounding States" reports that there are 645 public schools in Nevada, and that $16 \%$ of Nevada high schools are public. This adds up to approximately 103 public high schools in Nevada. Most of these public high schools would offer Spanish, Italian, and French. Others might offer Chinese, Japanese, Latin, German, etc. The high school we gave the questionnaire offers Spanish, French and Chinese.

It is important to know the reason why students still want to take foreign language when it is not mandatory, because it helps the language teachers know what their students want to learn from the class and know what they should be focusing on. This is going to improve the quality of teaching.

A 2010 New York Times study found that in this current decade, foreign language instruction has decreased in all languages except Chinese. The population who wants 
to learn Chinese keeps increasing. Compared to the data in 1997, the percentage of students choosing Chinese increased from one percent to four percent. Also the language education landscape is changed. "A decade ago, most of the schools with Chinese programs were on the East and West Coasts. But in recent years, many schools have started Chinese programs all around the United States" (Dilon).

\section{Growth in Chinese Language Courses}

Despite an overall decrease in foreign language instruction in American schools, more middle and high schools are offering classes in Chinese, according to a national survey.

Change in foreign languages offered in middle and high schools

\begin{tabular}{|c|c|c|c|}
\hline & $\begin{array}{l}\text { SCHOOLS } \\
\text { IN } 2008\end{array}$ & PERCENTAGE POINT CHANGE FR & FOM 1997 \\
\hline Chinese & $4.0 \%$ & & +3.0 \\
\hline Italian & 4.0 & & +1.0 \\
\hline Hebrew & 1.0 & & +0.8 \\
\hline Spanish & 93.0 & No change & \\
\hline Greek & 0.7 & -0.3 & \\
\hline Russian & 0.3 & -2.7 & 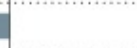 \\
\hline Japanese & 3.0 & -4.0 & \\
\hline Latin & 13.0 & -7.0 & \\
\hline German & 14.0 & -10.0 & \\
\hline French & 46.0 & -18.0 & \\
\hline
\end{tabular}

Fig. 1. Source: Growth in Chinese Language Courses. New York Times, 2010. Web. $5 / 20 / 2015$

\section{Research Designs}

There are multiple reasons that students in United States choose Chinese as their foreign language. I created a questionnaire to see the main reason that makes American public high school students choose Chinese as their foreign language (see Appen$\operatorname{dix}$ A).

I separated my questionnaire into two parts. The first part asks for personal information, which includes gender, grade level, the number of years spent studying Chinese, etc. The second part lists seven possible reasons why students choose to learn Chinese. They are:

1. I have a strong interest in Chinese and culture.

2. My parents encouraged me to study Chinese.

3. I think Chinese will improve my opportunities for higher education and a good career. 
4. My friends are taking Chinese.

5. I like the teacher.

6. I perceive Chinese to be easier than other languages offered at our school.

7. The school counselor advised me to study Chinese.

Chinese teacher in Nevada said she is going to have more Chinese classes next year. This shows that more and more students are interested in taking Chinese. The situation has changed from only one first year Chinese class last year, to two first year Chinese classes this year, to three first year Chinese classes next year. The number of new students in Chinese classes is constantly increasing.

\section{$3 \quad$ Findings and Analysis}

In the public high school, there are 1,609 students based on the report by US News. This semester, 61 students chose to take Chinese. There are two first-year Chinese classes and one second-year Chinese class. I offered a questionnaire in those three Chinese classes. Because 11 students were absent, I only sent out 50 questionnaires, and received 40 of them back, 39 of them being valid. Since the description for the second part of the questionnaire created a little confusion. Because of some of the students do not follow the introduction of the question, only 26 of the questionnaires had the second portion completed.

\subsection{General Analysis}

18 females and 21 males responded the questionnaire, as Figure 2 below shows. The gender distribution of the students taking first year Chinese and second year Chinese is shown in Table 1.
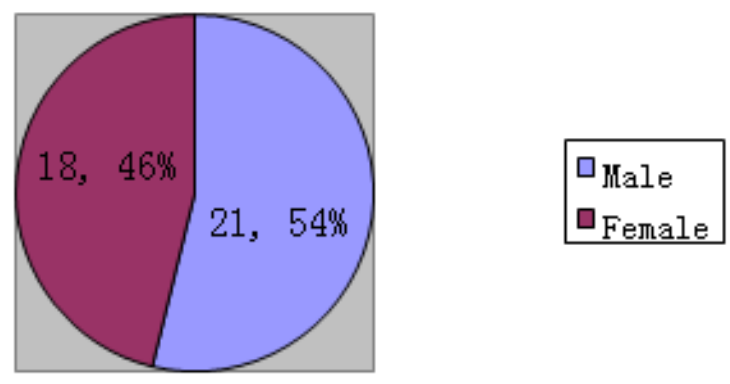

Fig. 2. The pie chart of the gender percentage of our respondents

Table 1. The gender distribution of the students taking first or second year Chinese

\begin{tabular}{|l|c|c|c|}
\hline & Male & Female & Total \\
\hline 1st year of Chinese & 16 & 13 & 29 \\
\hline 2nd year of Chinese & 5 & 5 & 10 \\
\hline Total & 21 & 18 & 39 \\
\hline
\end{tabular}


21 freshmen, 11 sophomores, 7 juniors, and 0 seniors responded to the questionnaire, as Figure 3 below shows. The grade level distribution of the students taking first year Chinese and second year Chinese is shown in Table 2.

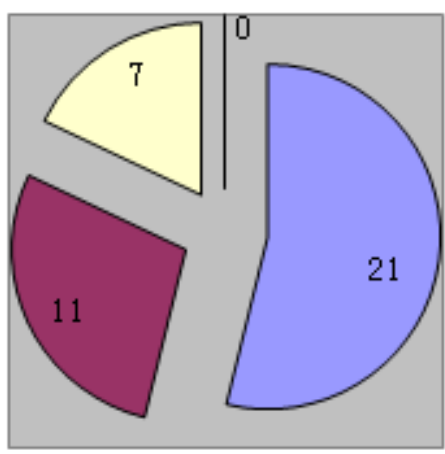

$$
\begin{aligned}
& \square_{9 \text { th }} \\
& \square_{10 \text { th }} \\
& \square_{11 \text { th }} \\
& \square_{12 \text { th }}
\end{aligned}
$$

Fig. 3. The pie chart of the grade level of our respondents

Table 2. The grade level distribution of the students taking first or second year Chinese

\begin{tabular}{|l|c|c|c|c|c|}
\hline & 9th & 10th & 11th & 12th & Total \\
\hline 1st year of Chinese & 21 & 4 & 4 & 0 & 29 \\
\hline 2nd year of Chinese & 0 & 7 & 3 & 0 & 10 \\
\hline Total & 21 & 11 & 7 & 0 & 39 \\
\hline
\end{tabular}

There is only one student whose mother speaks Chinese, and only one student whose father speaks Chinese. Two students' parents both speak Chinese, and the remaining 35 students all have parents who both do not speak Chinese, as Figure 4 below shows. The distribution of the students taking first year Chinese and second year Chinese is shown in Table 3.

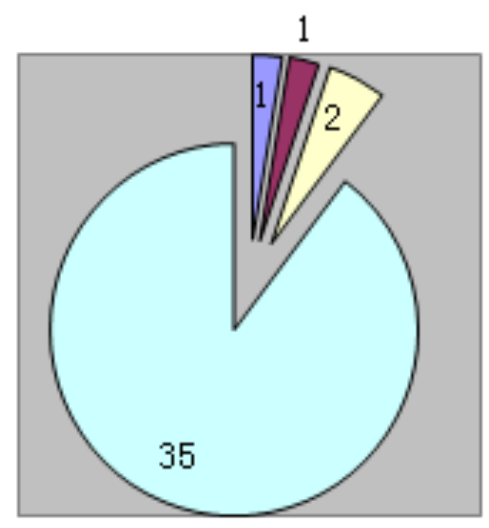

DMother

Father

Both

Dei ther

Fig. 4. The Pie chart of the family background of Chinese 
Table 3. of students' family background of Chinese speakers

\begin{tabular}{|l|c|c|c|c|c|}
\hline & Mother & Father & Both & Neither & Total \\
\hline $1^{\text {st }}$ year of Chinese & 1 & 1 & 0 & 27 & 29 \\
\hline $2^{\text {nd }}$ year of Chinese & 0 & 0 & 2 & 8 & 10 \\
\hline Total & 1 & 1 & 2 & 35 & 39 \\
\hline
\end{tabular}

\subsection{Hypothesises Tests}

R. C. Gardner's essay "Social Psychology and Second Language Learning The Role of Attitudes and Motivation" shows that success in second language learning is dependent on the students' natural ability in the language, the students' motivation in learning the language, and the influence of the people around them like family, teachers, and friends. Gardner posits that there are two kinds of motivation: Instrumental Motivation and Integrative Motivation. Instrumental Motivation means the students are motivated by possible future uses of the language, such as career opportunities it could offer. Integrative Motivation means the students are motivated by interest in the culture or history of the language-speaking country. Based on these theories, I generated seven possible reasons students may choose to learn Chinese in the second part of my questionnaire, which are listed below.

I have a strong interest in Chinese and Chinese culture. For high school students, learning another language is usually motivated by interest. Interest is one of the most important factors in encouraging students to learn Chinese.

My parents encouraged me to study Chinese. For high school students, the suggestion and encouragement is another factor that influences a students' decision. The more the parents value Chinese, the more motivation the student may have. Conversely, if the family doesn't like Chinese, the attitude that the family has may also decrease the student's interest in learning Chinese.

I think Chinese will improve my opportunities for higher education and a good career. For these students, they know that language is a necessary skill in the job market. As China is currently undergoing major development, there will be increased interaction between China and America. The fact that the language might be useful in the future may also help to motivate students.

My friends are taking Chinese. The students who choose this as the main motivating factor are highly influenced by friends, and learning a language with a friend also could help motivate students.

I like the teacher. Sometimes a good teacher can make students have a greater interest in the subject.

I perceive Chinese to be easier than other languages offered at our school. Sometimes because of their family background, Chinese may be easier for certain students. Or some students tried to learn other languages, but based on their abilities, came to believe that Chinese is easier.

The school counselor advised me to study Chinese. In this situation, students mostly just wants to fill their graduation requirements. Maybe some students really disliked other languages that the school offered. 


\subsection{Statistic Analysis}

This part discusses the primary reason why students chose Chinese as their foreign language class. Because the description of the second part of the questionnaire created some confusion, only 26 of the questionnaires had a completed second portion. The students were supposed to label these seven reasons from one to seven, one being the most important reason and seven being the least important reason.

I used the weighted mean to compare the importance of these seven reasons. For easy calculating, if a student thinks that the first reason is the most important, then the first question would receive a score of one. If the student believed it were second most important, then the question would receive a score of two. This continues to a score of seven, where the student believes it was the least important reason, and so the question gets a score of seven. The less the weighted mean there is, the more importance the question has. The result are shown in table 5 in the next page.

Comparing the weighted mean (x), these seven reasons are listed in terms of their importance below with $\bar{x}$ values in parentheses:

- I have a strong interest in Chinese and culture.

- I think Chinese will improve my opportunities for higher education and a good career.

- My parents encouraged me to study Chinese.

- I like the teacher.

- My friends are taking Chinese.

- I perceive Chinese to be easier than other languages offered at our school.

- The school counselor advised to study Chinese.

The analysis of a comparison of the opinion from the male students and female students is shown below. In these 26 students, the weighted mean of the 12 male students and 14 female students is shown in Table 4.

Table 4. the weighted mean of total, male and female with these questions

\begin{tabular}{|l|c|c|c|}
\hline \multicolumn{1}{|c|}{ Weighted mean( $(\overline{\mathbf{x}})$ Reasons } & Total & Male & Female \\
\hline I have a strong interest in Chinese and culture & 1.85 & 2.17 & 1.57 \\
\hline My parents encouraged me to study Chinese. & 4.00 & 3.50 & 4.42 \\
\hline $\begin{array}{l}\text { I think Chinese will improve my opportunities for } \\
\text { higher education and a good career. }\end{array}$ & 2.35 & 2.25 & 2.42 \\
\hline My friends are taking Chinese. & 4.31 & 4.42 & 4.21 \\
\hline I like the teacher. & 4.23 & 4.42 & 4.07 \\
\hline $\begin{array}{l}\text { I perceive Chinese to be easier than other languages } \\
\text { offered at our school. }\end{array}$ & 5.58 & 5.33 & 5.79 \\
\hline The school counselor advised me to study Chinese. & 5.69 & 5.91 & 5.50 \\
\hline
\end{tabular}

Using a two sample t-test on a TI-Nspire calculator, which is the program (tTest_2Samp), with the alternate hypothesis that male and female have a significant difference in opinion on these reasons, I got $\mathrm{t}=0.0036$ and $\mathrm{p}=0.997$. Because the $\mathrm{p}$ Value is greater than 0.05 , we reject the alternate hypothesis, and can say that the 
male and female populations don't have a significant difference in opinion in these questions.

The order of importance of the reasons for male, female, and the whole sample population is shown in Table 5 below.

Table 5. the importance order for male students and female students

\begin{tabular}{|l|c|c|c|}
\hline \multicolumn{1}{|c|}{ Order of importance Reasons } & Total & Male & Female \\
\hline I have a strong interest in Chinese and culture & 1 & 1 & 1 \\
\hline My parents encouraged me to study Chinese. & 3 & 3 & 5 \\
\hline $\begin{array}{l}\text { I think Chinese will improve my opportunities for higher educa- } \\
\text { tion and a good career. }\end{array}$ & 2 & 2 & 2 \\
\hline My friends are taking Chinese. & 5 & 4 & 4 \\
\hline I like the teacher. & 4 & 4 & 3 \\
\hline $\begin{array}{l}\text { I perceive Chinese to be easier than other languages offered at } \\
\text { our school. }\end{array}$ & 6 & 6 & 7 \\
\hline The school counselor advised me to study Chinese. & 7 & 7 & 6 \\
\hline
\end{tabular}

Based on these results, male students have exactly the same order as the whole sample population. Even though there is a small difference between the female opinions and the whole sample opinions, this is not because of a significant difference in calculation, but the small sample size.

Overall, both male and female students chose the first and third reason as their primary reason. The second, fourth, and fifth reasons' importance do not differ significantly, but the weighted mean is significantly higher than the first and third reason. The sixth and seventh reason have the highest weighted mean, meaning people don't think they are important.

The analysis of the comparison between the opinion from the male students and female students is shown below. In these 26 students, the weighted mean of 19 first year Chinese students and 7 second year Chinese students is shown in Table 6.

Table 6. the weighted mean of the student in $1^{\text {st }}$ year Chinese class and $2^{\text {nd }}$ year Chinese class

\begin{tabular}{|l|c|c|c|c|}
\hline \multicolumn{1}{|c|}{ Weighted mean( $\overline{\mathbf{x}})$ and importance order Reasons } & \multicolumn{2}{c|}{ 1st year } & \multicolumn{2}{c|}{ 2nd year } \\
\hline I have a strong interest in Chinese and culture & 2.00 & 1 & 1.43 & 1 \\
\hline My parents encouraged me to study Chinese. & 3.95 & 3 & 4.14 & 3 \\
\hline $\begin{array}{l}\text { I think Chinese will improve my opportunities for higher } \\
\text { education and a good career. }\end{array}$ & 2.37 & 2 & 2.29 & 2 \\
\hline My friends are taking Chinese. & 4.26 & 5 & 4.43 & 4 \\
\hline I like the teacher. & 4.10 & 4 & 4.57 & 5 \\
\hline $\begin{array}{l}\text { I perceive Chinese to be easier than other languages offered } \\
\text { at our school. }\end{array}$ & 5.57 & 6 & 5.57 & 6 \\
\hline The school counselor advised me to study Chinese. & 5.74 & 7 & 5.57 & 6 \\
\hline
\end{tabular}

Based on these results, the importance order of the first year Chinese class students is exactly the same as the whole sample population's importance order. The second 
year Chinese class students are mostly the same, but it is mainly because the sample size is very small, containing only seven students. This results in the same conclusion as the previous section, in which the first and third reason are more important than the remaining five.

16 out of 39 students said that they have other reasons for learning Chinese aside from the ones provided. This percentage is shown below in Figure 5 as a pie chart.
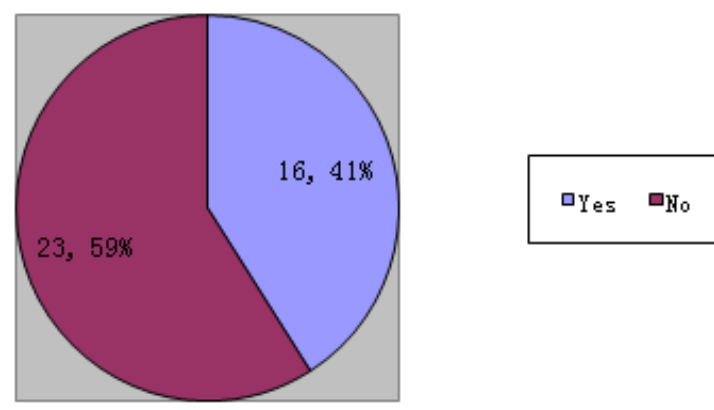

Fig. 5. the pie chart of students who have other reason to choose Chinese

These sixteen reasons can be separated into several parts. The reasons in the first part are about interest in the language. It includes:

- I think Hanzi is very artistic.

- I'd like to travel to China and teach there, and eat the food there.

- I was curious how the character system worked.

- I wanted to see what it was like.

- It was just interested in the character system.

- Learn a new language.

The second part is because of the graduation requirements, or because Chinese is a good fit.

- Required for an honors diploma and most kids don't take it. I thought it would help challenge me.

- I did not do well with Spanish.

- I didn't want to take Spanish or French.

- I didn't choose Chinese.

- The third group thought that Chinese is useful.

- I figure it will be useful, considering how it is the most spoken language in the world.

- As an IB student and global citizen, it is very important to understand other cultures, and languages. It is a special opportunity to converse with others in their native tone.

- The fourth part is about familial influence on the student choice. In includes:

- My mom would not let me take French, so Chinese seemed cool.

- My sister lived in Taiwan. 


\section{Conclusions and Highlighted Findings}

As of now, the establishment of Chinese classes in American public high school is still in its infancy. In fact, for American students, Chinese is a very hard language course. The Foreign Service Institute (FSI) places all the languages in the world into three categories based on the approximate learning time (Thompson). Mandarin Chinese is in the third category, which is the hardest category, needing approximately more than 2,200 hours and a year to learn. For English speakers, the extremely difficult writing system makes the learning process even harder.

Based on my experience in the public school's Chinese class, even the worst students in the class were very interested in Chinese culture. Most of the time, students were interested in China, but could not motivate themselves to learn Chinese. Learning a language requires a lot of effort, memorization, and time. Most American public school students cannot spend a majority of their free time practicing a foreign language. If there are more situation that need Chinese to communicate, this situation may change. There is a group of students who take Chinese just to fulfill the graduation requirement. The motivation to actually learn Chinese in these students is very low. I see a lot of students in the class who simply just finish the work that is required. If they are allowed write Chinese in pinyin, which is an easier system then Chinese character, but not useful to use, they do not put in the effort of writing words in Chinese characters.

\section{$5 \quad$ References}

[1] Nevada Education Data Book. Research Division of the Legislative Counsel Bureau, 2013. Web. 5/30/2015.

[2] C. Rhodes, Nancy and Pufahl, Ingrid. Foreign language teaching in us schools. Center For Applied Linguistics. November, 2009. Web. 5/30/2015.

[3] Dillon, Sam. Foreign Languages Fade in Class - Except Chinese. New York Times, 2010. Web. 5/30/2015.

[4] Dornyei, Zoltan. "Motivation in second and foreign language learning". Thames Valley University, London. June 12, 2009. Web. 5/30/2015.

[5] Earl Wooster High School Overview. US News. Web. 5/30/2015.

[6] "High School Graduation Requirements: Foreign Language". Education Commission of the State. March 23, 2007. Web. 5/30/2015.

[7] States with or Considering High School Foreign Language Graduation Requirements Revised March 2010. National Council of State Supervisors for Language. Web. 5/30/2015.

[8] Thompson, Irene. "Language Learning Difficulty". About World Language. March 11, 2014. Web. 5/30/2015.

\section{Author}

Haihuai He is a teacher of Wenzhou Vocational \& Technical College, Zhejiang, China.

Article submitted 01 May 2017. Published as resubmitted by the author 14 June 2017. 